\title{
Novel Mutations of ATP7B Gene in Iranian Patients with Wilson's Disease
}

\author{
Iradj Maleki ${ }^{\text {* }}$, Mohammad Reza Zali ${ }^{2}$, Hossein Najm Abadi ${ }^{3}$ \\ ${ }^{1}$ Department of Internal Medicine, Mazandaran University of Medical Sciences, Sari, Iran. \\ ${ }^{2}$ Research Center of Gastroenterology and Hepatology, Shahid Beheshti University of Medical Science, Tehran, Iran. \\ ${ }^{3}$ Research Center of Genetics, Rehabilitation University of Tehran, Tehran, Iran.
}

Received: 27 May 2012

Revised: 12 Sep 2012

Accepted: 20 Feb 2013

Corresponding Author:

Iradj Maleki

Department of Internal Medicine,

Mazandaran University of Medical

Sciences, Sari, Iran

Phone:+98-11226170-4

E-mail: iradj2001@yahoo.com

\begin{abstract}
Background: Wilson's disease is a rare autosomal recessive disorder characterized by toxic accumulation of copper in liver and brain. The disorder is caused by mutations in the ATP7B gene, encoding a copper transporting P-type ATPase. Characterization of the spectrum of mutations in this gene is important both for diagnosis and genetic counseling of the families.

Materials and Methods: We enrolled 30 definitely diagnosed patients (ages ranging from 3 to 33 ). Genomic DNA was extracted from peripheral blood samples. All the exons of the gene were amplified by polymerase chain reaction using specified primers for each exon. The amplification products were then analyzed by direct automated sequencing.

Results: $87 \%$ of our patients had liver problems while $47 \%$ of suffered from neurological problems. In this study we will report the spectrum of mutation found among Iranian families, which are mainly different from other reports.

Conclusion: By performing the present study, some new mutations in ATP7B gene, Del C 3696(1232) and S1369L were identified for the first time in Wilson's disease patients.
\end{abstract}

Keywords: Wilson's disease; ATP7B; Mutation detection; Iran

Please cite this article as: Motavalli Haghi SM, Fakhar M, Sharif M, Paghe A, Sharbatkhori M, Tavakoli R, Gholami SH. Molecular Identification of Ovine Babesia spp. in North of Iran. Res Mol Med. 2013; 1 (1): 43-46

\section{Introduction}

Wilson's disease (WD) is a rare genetic disorder of copper metabolism with a worldwide incidence of 30 cases per million, a gene frequency of $0.56 \%$ and a carrier frequency of 1 in 90 (1). The disorder is caused by mutations in the ATP7B gene, which is located on chromosome 13q14.3 (2).

ATP7B gene regulates copper transportation into bile from hepatocytes. Copper incorporates into apoceruloplasmin to form ceruloplasmin (major copper carrier in blood). ATP7B dysfunction cause toxic accumulation of copper in liver and brain (3) that resulted in neurological and hepatic manifestations. Therefore, ATP7B dysfunction forms unstable apoceruloplasmin that is rapidly degraded (4) and the level of ceruloplasmin will be decreased. WD manifestations include bradykinesia, tremor, chorea, dystonia,iigidity and especially Kayser-Fleischer ring (KF ring) in eye; in addition other neurological presentations are myoclonic epilepsy, cerebellar ataxia, cognitive deterioration and proximal muscle weakness (5). Also WD has heterogenous neurological manifestation and is similar to neurological disorders that resulted in delay diagnosis (6).

Diagnosis of the disease is based on clinical findings, laboratory tests and good response to medication, but none of these findings are pathogonomic.

Characteristics of the Wilson's disease gene (OMIM 277900) which codes for a copper transporting P-type ATPase (ATP7B) has resulted in a major breakthrough for understanding the pathophysiology of WD, but the role of genetic testing in the clinical management of the patients is not yet established and for clinical purposes, the use of mutation analysis is limited by the occurrence of more than 200 mutations related to WD worldwide $(2,7)$. ATP7B mutations are associated with lower ceruloplasmin oxidase levels and earlier age of onset WD disease, serum ceruloplasmin can help to predict ATP7B mutations and facilitate the mutations analysis (8). Screening of patient's first degree relatives is valuable in early 
diagnosis and management and avoidance of irreversible complications (9). Although WD has monogenic inheritance but sometimes genetic prevalence and the number of clinical diagnosis are different, but due to reduced penetrance of ATP7B mutation and difficulty in diagnosis, some patients are missed (10).

As regards to high prevalence of WD in Iran because of consanguinity (11), in this study we will report on the mutational spectrum of ATP7B gene among Iranian populations with WD.

\section{Materials and Methods}

Between 200-2001, 33 patients with a diagnosis of WD were enrolled. Patients were found either based on review of previous registries or by referral from other colleagues. These patients were selected according to routine diagnostic criteria for WD (Table1) and those patients who had suspicious laboratory results underwent another laboratory tests.

Table 1. Diagnostic criteria for our patients to enter the study.

$\begin{array}{ll}1 & \downarrow \text { Serum Cereloplasmin } \\ 2 & \downarrow \text { Serum Copper } \\ 3 & \uparrow 24 \text { hour Urinary Copper Excretion }>100 \mu \mathrm{g} / 24 \mathrm{~h} \\ 4 & \text { Liver biopsy: } \uparrow \text { hepatic copper content }\end{array}$

Also patients were fully examined and referred to an ophthalmologist. We performed blood sampling of 10 cc on each of our patients and after centrifuge, serum component was sent to DNA extraction center, where two specialists performed the genomic DNA extraction procedure. Genomic DNAs were extracted in 24-36 hours.

And because at that time, assessment of mutations in ATP7B gene was only done in some limited centers through the world, our samples were sent to Charite Campus Mitte Center in Berlin, Germany (fifteen samples for the first time and the other eighteen samples for the second time) and final results were reported to us after 5 months.

Table 2. Prevalence of liver and neurological problems according to patients' sex.

\begin{tabular}{lll}
\hline Problem & Male & Female \\
\hline Liver problems & 13 & 13 \\
Neurological problems & 8 & 6 \\
\hline
\end{tabular}

\section{Results}

During these procedures, 3 patients were excluded from the study because of poor DNA sampling; so our final cases were 30 patients with an equal sex distribution and a mean age of 16 years (ranging 3 to 33 years). Liverproblems including icter, hepatomegaly, ascites acute hepatic failure and encephalopathy was reported in $26(87 \%)$ patients. This prevalence was equal in both sexes with 13 female and 13 male patients. Also $47 \%$ of our patients (14 patients including 6 females and 8 males) had neurological problems like dystonia, muscular spasm, rigidity, mood disorders andmental retardation (Table.2).

Kayser-Fleischer ring was detected in 21 (70\%) patients. $43 \%$ of the patients had a positive family history that was always their brothers and sisters in addition to two separate cases in cousins and one case in an uncle and none of the parents had the disease. All of our patients except one of them were single.

Table 3. Identified mutations in ATP7B gene of Iranian patients.

\begin{tabular}{|c|c|c|c|}
\hline Patient & Sex & Age & Mutation \\
\hline 1 & Female & 21 & D642 H / - \\
\hline 2 & Female & 14 & N $1270 \mathrm{~S} / \mathrm{N} 1270 \mathrm{~S}$ \\
\hline 3 & Male & 16 & $-1-$ \\
\hline 4 & Female & 12 & R $778 \mathrm{~W} /$ - \\
\hline 5 & Female & 11 & $-1-$ \\
\hline 6 & Male & 17 & R 778 G / - \\
\hline 7 & Female & 17 & (1232)3696 Del C / (1232)3696 \\
\hline \multicolumn{4}{|r|}{ (a } \\
\hline 8 & Male & 26 & N 1270 S / D 642 H \\
\hline 9 & Female & 18 & R $148 \mathrm{~W} / \mathrm{R} 148 \mathrm{~W}$ \\
\hline 10 & Male & 14 & Q 1142 X/ R 919 W \\
\hline 11 & Male & 30 & $-75 \mathrm{~A}->\mathrm{C} /-75 \mathrm{~A}->\mathrm{C}$ (IVS12 - \\
\hline $2 \mathrm{~A} / \mathrm{C}) 12$ & Female & 9 & D $642 \mathrm{H} / \mathrm{D} 642 \mathrm{H}$ \\
\hline 13 & Female & 36 & S $1369 \mathrm{~L} /(546) 1638 \mathrm{DelC}(-75 \mathrm{~A}$ - \\
\hline \multicolumn{4}{|l|}{$>$ C) } \\
\hline 14 & Female & 18 & $-1-$ \\
\hline 15 & Male & 18 & N $1270 \mathrm{~S} / \mathrm{N} 1270 \mathrm{~S}$ \\
\hline 16 & Female & 10 & R 969 Q / G 591 D \\
\hline 17 & Male & 10 & Q $1142 \mathrm{Amb} / \mathrm{Q} 1142 \mathrm{Amb}$ \\
\hline 18 & Male & 15 & 845 Del T / 845 Del T \\
\hline 19 & Female & 20 & Q $680 \times(\mathrm{Amb}) / \mathrm{Q} 680 \times(\mathrm{Amb})$ \\
\hline 20 & Female & 19 & Q $1142 \mathrm{Amb} / \mathrm{Q} 1142 \mathrm{Amb}$ \\
\hline 21 & Male & 13 & L 939 Amb / L 939 Amb \\
\hline 22 & Female & 3 & 3649-3645 Del gttctg /3649-3645 \\
\hline \multicolumn{4}{|l|}{ Del gtt } \\
\hline 23 & Male & 10 & $-1-$ \\
\hline 24 & Male & 8 & L 1299 R / L 1299 R \\
\hline 25 & Male & 8 & N $1270 \mathrm{~S} / \mathrm{-}$ \\
\hline 26 & Male & 8 & H 1069 Q / H 1069 Q \\
\hline 27 & Female & 16 & $-1-$ \\
\hline 28 & Male & 15 & G 1089 E / G 1089 E \\
\hline 29 & Male & 9 & I $857 \mathrm{~T} / \mathrm{I} 857 \mathrm{~T}$ \\
\hline 30 & Female & 33 & D642 H / D642 H \\
\hline
\end{tabular}

Moreover, low ceruloplasmin level in 26 (87\%) patients, low serum copper level in $23(76 \%)$ patients and increased copper in 24 hour urine in 28 (93\%) patients were detected. Assessment of copper in dry 
weight liver was only performed on five cases that were 5-40 times of normal range.

Mutations detected in ATP7B gene of our patients had a wide range of variety (Table 3 ) and they were completely different from the mutations found in European patients. In this study we found some new mutations such as Del C 3696(1232) and S1369L that were not reported up to the time we did our study.

\section{Discussion}

Wilson's disease is a rare autosomal recessive disorder. Wilson's disease usually presents with inflammation and chronic liver failure, brain basal ganglia degeneration and Kayser-Fleischer ring in cornea $(2,7)$ The symptoms are due to impaired bile exertion and copper deposition in organs like liver, central nervous system, kidney and cornea. These abnormalities result from mutations in ATP7B, which is located on chromosome 13. ATP7B produces an adenosine three phosphatase (ATPase) that consists of 1443 amino acids (2-9). This membrane protein has 6 binding sites for copper and several sites for phosphorylation and ATPase $(2,12)$. There is no gold standard for diagnosis of Wilson's disease. Diagnosis requires a combination of clinical and biochemical tests. None of these parameters alone allows a certain diagnosis of WD.

Although DNA sequencing made breakthrough in identifying pathophysiology of the disease, this strategy is limited since currently over 320 mutations and 80 polymorphisms have been identified. But in certain populations, a high prevalence of particular mutations allows rapid screening and diagnosis of the disease and in this field many studies were conducted through the world.

Importance of diagnosis is for its role in prevention of morbidity and mortality, early diagnosis result in early treatment. Some variants are associated with ATP7B dysfunction and cause its mislocalization so reduce ATP7B stability; it shows genotype and phenotype correlation and mechanism of disease pathogenesis (13). Two microsatellites, D13S301 and D13S314, are introduced for analysis and detection carriers and affected patient without symptoms (14). In 2006 Margarit et al, (15), identified ATP7B alterations in 60 Spanish patients with WD from 40 different families, by PCR amplification, singlestrand conformation polymorphism (SSCP) analysis and sequencing and 21 different ATP7B gene mutations were identified, eight of which were novel. WU ZY et al, in 2006 (16), demonstrated that there is no correlation between MURR1 gene (that was thought, it may influence human copper metabolism and the clinical presentations of the disease) and WD in their 218 unrelated Chinese patients.
Zali et al clarified a biomarker, H1069Q, as the most frequent mutation in north and central region of Iran which is useful for rapid detection assay and early diagnosis of WD patients (17). Galehdari and Tangestani found a homozygous pathogenic misssense mutation at codon 778 (R778W) in Iranian patients that previously reported in American and European population (11). Dastsooz et al studied mutations in exon 8 and 14 of ATP7B gene and identified a novel mutation, c.2335T $>\mathrm{G}$, in Iranian population, this mutation demonstrates severe neuropsychiatric condition in patients (18).

In another study by Wan et al in 2006, ten different mutations were identified among 29 Taiwanese WD patients; four of them were novel (Ala1168Pro, Thr1178Ala, Ala1193Pro, and Pro1273Gln) (19), while in India, three mutations, Q1256R, A1003T and $\mathrm{I} 1102 \mathrm{~T}$, were characterized in WD patients, using SSCP and DNA sequencing (20).

In our experience; although, because of some financial concerns, we did not entered many patients in our study, like other parts of the world, spectrum of mutations had a large variety; and the most prevalent of them, N1270S/D642H, was only detected in $10 \%$ of our patients. And prevalent mutations like H1069Q in European WD patients or R778L in WD patients from the Far East were rare in our patients. Nonetheless Zali et al observed H1069Q mutation which is located in exon 14 in Iranian patients with hepatic presentation, exon 14 is known as hot spot for its several mutations (21).

Moreover, (1232)3696 Del C and S1369L mutations were reported for the first time in WD patients. Interestingly, in 17 (57\%) patients, the same mutation occurred in the two alleles, which is probably due to familial and local marriages. In assessment of probable correlation between types of mutations and hepatic or neurological presentations of the disease (genotype-phenotype correlation), we could not reach a result because of small number of our patients. It seems that more studies should be done on large number of patients and in different countries $(16,19)$.

\section{Conclusion}

By performing this study, for the first time we identified mutations in ATP7B gene of Wilson's disease in Iranian patients and some new mutations in ATP7B gene (Del C 3696(1232) and S1369L), were reported for the first time in WD patients.

\section{Acknowledgement}

The authors acknowledge Dr. Naser Ebrahimi Daryani, Dr. Najafi, Dr. Allahverdi, Dr. Nakhaee and Dr. Talachian to their valuable role in referring patients. 


\section{References}

1. Dedoussis GV, Genschel J, Sialvera TE, et al. Wilson disease: high prevalence in a mountainous area of Crete. Ann Hum Genet. 2005; 69 (Pt 3): 268-274. PMID: 15845031

2. Sherlock S, Dooley J. The portal venous system and portal hypertension. Diseases of the liver and biliary system. 1997; 8:151207.

3. Behari M, Pardasani V. Genetics of Wilson disease. Parkinsonism Relat Disord. 2010; 16(10): 639-44. PMID 20708958

4. Kojimahara N, Nakabayashi H, Shikata T, Esumi M. Defective copper binding to apoceruloplasmin in a rat model and patients with Wilson's disease. Liver. 1995; 15(3): 135-42. PMID: 7674840

5. Nagao K. What's your diagnosis?Wilson disease (hepatolenticular degeneration) with Keyser-Fleischer ring. J Pediatr Ophthalmol Strabismus. 2007; 44 (2):84, 111. PMID: 17410957

6. Soltanzadeh A, Soltanzadeh P, Nafissi S, Ghorbani A, Sikaroodi H , Lotfi J. Wilson disease: a great masquerader. Eur Neurol. 2007; 57(2):80-5. PMID: 17179709

7. Cox DW, Roberts EA. Wilson disease. In: Mark Feldman et al, editors: Sleisenger and Fordtran's Gastrointestinal and liver disease. 6th ed. Philadelphia: W.B. Saunders Company; 1998. P. 1104-1110

8. Merle U, Weiss KH, Eisenbach C, Tuma S, Ferenci P, Stremmel W. Truncating mutatioms in the Wilson disease gene ATP7B are associated with very low serum ceruloplasmin oxidase activity and an early onset of Wilson disease. BMC Gastroenterol. 2010, 10:8. PMID: 20082719

9. Ferenci P. Wilson's Disease. Clin Gastroentrol Hepatol. 2005; 3(8): 726-733. PMID: 16233999

10. Coffey AJ, Durkie M, Hague S, McLay K, Emmerson J, Lo C, et al. A genetic study of Wilson's disease in the United Kingdom. Brain, 2013; 136(Pt 5): 1476- 87. PMID: 23518715

11. Galehdari H, Tangestani R. Molecular Genetics Diagnosis of Wilson Disease: The First Reported Case of ATP7B Gene Mutation at Codon 778 in Southwest Iran. Iran J Pathol. 2012; 7 (4): 262-6.
12. Stemlieb I. Hepathology: A centuary of progress (Wilson disease). Clin Liver Dis. 2000; 4(1): 229-239. PMID: 11232186

13. Huster D, Kühne A, Bhattacharjee A, Raines L, Jantsch V, Noe J, Schirrmeister W, et al. Diverse functional properties of Wilson disease ATP7B variants. Gastroenterology. 2012, 142(4): 947-956. PMID: 22240481

14. Azimi N, Jabbarpour Bonyadi M, Soumi MH, Rafiei M, Sarami F, Mohammadian R, et al. Application of microsatellites in genetically analysis of affected families with wilson's disease from east and west Azarbaijan. Medical journal of mashhad university of medical sciences, 2007; 461-8.

15. Margarit E, Bach V, Gomez D, et al. Mutation analysis of Wilson disease in the Spanish population -- identification of a prevalent substitution and eight novel mutations in the ATP7B gene. Clin Genet. 2005; 68(1): 61-68. PMID: 15952988

16. Wu ZY, Zhao GX, Chen WJ, et al. Mutation analysis of 218 Chinese patients with Wilson disease revealed no correlation between the canine copper toxicosis gene MURR1 and Wilson disease. J Mol Med. 2006; 84(5): 438-442. PMID: 16649058

17. Zali N, Mohebbi SR, Esteghamat S, Chiani M, Montazer Haghighi M, Hosseini -Asl MK, et al. Prevalence of ATP7B gene mutations in Iranian patients with Wilson disease. Hepat Mon. 2011; 11(11):890-4. PMID: 22308153

18. Dastsooz H, Dehghani SM, Imanieh MH, Haghighat M, Moini $\mathrm{M}$ and Fardaei M.A new ATP7B gene mutation with severe condition in two unrelated Iranian families with Wilson disease. Gene. 2013; 514(1):48-53. PMID: 23159873

19. Wan L, Tsai CH, Tsai Y, et al. Mutation analysis of Taiwanese Wilson disease patients. Biochem Biophys Res commun. 2006; 345(2): 734-8. PMID: 16696937

20. Kumar S, Tapa BR, Kaur G, et al. Familial gene analysis for Wilson disease from north-west Indian patients. Ann Hum Biol. 2006; 33(2): 177-86. PMID: 16684691

21. Zali N, Mohebbi SR, Esteghamati S, Firouzi F, Hosseini Asl SMK, Chiani M, et al. Mutation spectrum of 7 exons of ATP7B gene in Iranian patients with Wilson disease. Gastroenterol Hepatol Bed Bench 2009; 1(1):39. 